\title{
ANNOUNCEMENT \\ 1971 Annual Meetings of the American Pediatric Society and the Society for Pediatric Research
}

Traymore Hotel, Atlantic City, New Jersey

Wednesday, April 28, 8:30 PM DOES COMPREHENSIVE CARE MAKE

A DIFFERENCE? A symposium sponsored by the American Pediatric Society, the Society for Pediatric Research, and the Ambulatory Pediatric Society

Thursday, April 29

Plenary Session, American Pediatric Society

Friday, April 30 Subspecialties Session, The American Pediatric

Saturday, May 1 Society and The Society for Pediatric Research Plenary Session, Society for Pediatric Research

For information write to Charles D. Cook, M.D. (Secretary, American Pediatric Society, 333 Cedar Street, New Haven, Connecticut 06510) or Robert E. Greenberg, M.D. (Secretary, Society for Pediatric Research, 12012 Compton Avenue, Los Angeles, California 90059). 